\title{
Potential Inhibitors of Chemokine Function: Analysis of Noncovalent Complexes of CC Chemokine and Small Polyanionic Molecules by ESI FT-ICR Mass Spectrometry
}

\author{
Yonghao Yu, ${ }^{*}$ Matthew D. Sweeney, ${ }^{\dagger}$ Ola M. Saad, ${ }^{\ddagger}$ and Julie A. Leary \\ Genome Center, Departments of Chemistry and Molecular Cell Biology, University of California, Davis, \\ California, USA
}

\begin{abstract}
Chemokines play a critical role in inducing chemotaxis, extravasation, and activation of leukocytes both in routine immunosurveillance and autoimmune diseases. Traditionally, to disrupt chemokine function, strategies have focused on blockage of its interaction with the receptor. Recently, it has been demonstrated that binding to glycosaminoglycans (GAGs) is also required for the in vivo activity of many chemokines. Thus, interference with the GAG-binding of chemokines may offer an alternative, valid, anti-inflammatory strategy. However, the potential of using small polyanions to inhibit the interactions between chemokines and cell surface GAGs has not been fully explored. In this study, a mass spectrometry based filtration trapping assay was utilized to study the interactions between two CCR 2 ligands (MCP-1/CCL2 and MCP-3/CCL7) and a series of low molecular weight, polyanionic molecules. Findings were confirmed by using a hydrophobic trapping assay. The results indicated that Arixtra (fondaparinux sodium), sucrose octasulfate, and suramin were specific binders of the chemokines, while cyclodextrin sulfate, although the most highly sulfated molecule among the ones investigated, showed no binding. The binding stoichiometry of the small molecule ligand was determined from the measured molecular weight of the noncovalent complex. Furthermore, the dissociation constant between MCP-3 and Arixtra was determined by using electrospray ionization Fourier transform ion cyclotron resonance (ESI FT-ICR) mass spectrometry, which compared favorably with the result of the isothermal titration calorimetry (ITC) assay. The relative binding affinity of these ligands to MCP-3 was also determined using a competitive filtration trapping assay. (J Am Soc Mass Spectrom 2006, 17, 524-535) (C) 2006 American Society for Mass Spectrometry
\end{abstract}

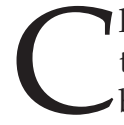
hemokines are small $(8-10 \mathrm{kDa})$, secreted proteins that have a critical role in a wide range of biological processes, including development, lymphocyte homing, wound repair, and inflammation $[1,2]$. In addition to binding to, and signaling through, the cell surface G-protein coupled receptors (GPCRs), GAG binding is also one of the conserved properties of chemokines and is critical for their in vivo functions [3-5]. The specific interactions [6] of chemokines with GAGs provide a mechanism for cell-surface retention and presentation, especially in the presence of shear forces [3]. The relevance of GAG binding in chemokine function in vivo has been shown using a mouse perito-

Published online February 28, 2006

Address reprint requests to Dr. J. A. Leary, Genome Center, Department of Chemistry and Molecular Cell Biology, University of California at Davis, One Shields Road, Davis, CA 95616, USA. E-mail: jaleary@ucdavis.edu

* Also with the Department of Chemistry, University of California at Berkeley, Berkeley, CA.

t Also with the Department of Molecular and Cell Biology, University of California at Berkeley, Berkeley, CA.

‡Present address: Genentech, Inc., South San Francisco, CA 94080. neal cell recruitment assay [7]. In contrast to the wildtype chemokine that is effectively retained at the site of injection, the non-GAG-binding chemokine mutant moves rapidly out of the original tissue compartment. Not surprisingly, this variant, unlike the wild-type chemokine, was unable to recruit cells in vivo.

In another example, the critical role of the cell surface GAG in chemokine-mediated cell recruitment has been demonstrated in mice with inactivated NDST-1 ( $N$ acetyl glucosamine $\mathrm{N}$-deacetylase- $\mathrm{N}$-sulfotransferase- 1 ) [8]. This enzyme adds sulfate to heparan sulfate (HS) chains during biosynthesis, and the mutation leads to a significant attenuation in $\mathrm{N}$-sulfation of the HS isolated from endothelial cells. It was observed that chemokine transcytosis and presentation at the lumenal surface in the mutant mice were significantly reduced, resulting in decreased neutrophil firm adhesion, migration, and, as a result, infiltration.

To date, anti-inflammatory strategies have mainly focused on inhibiting the chemokine-receptor interaction using small molecules, soluble receptors (chemokine binding proteins), and antibodies [4]. It has been 
(a)

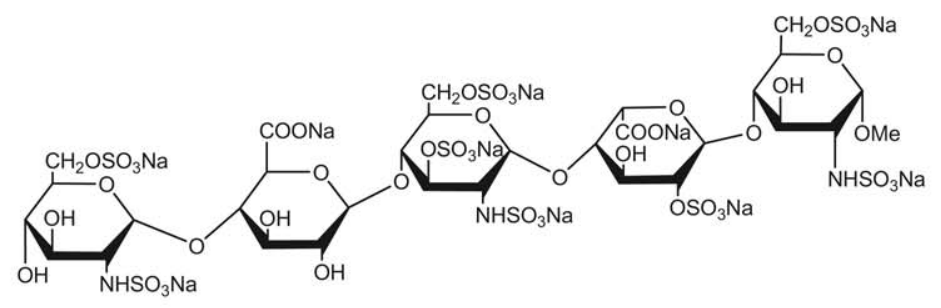

(c)

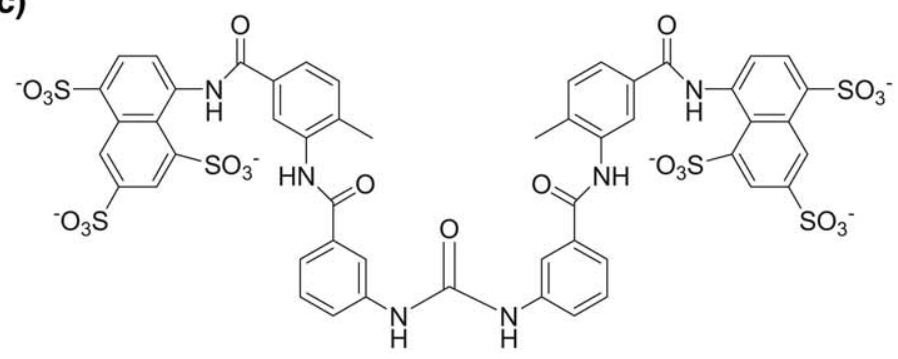

(b)

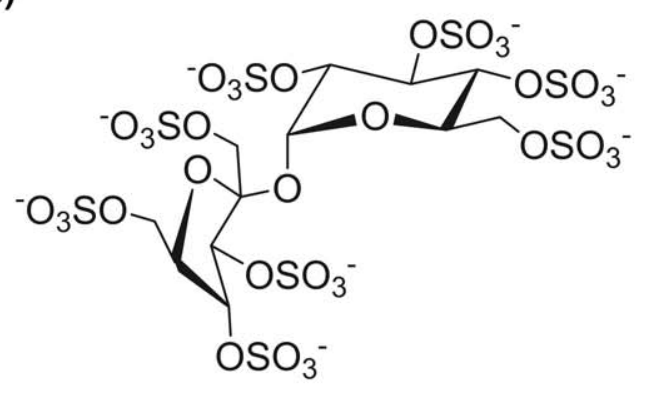

(d)

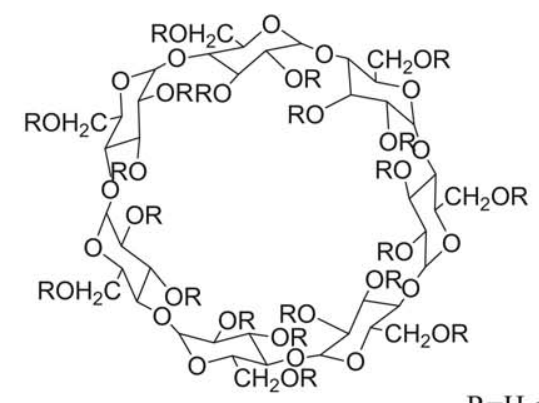

(e)

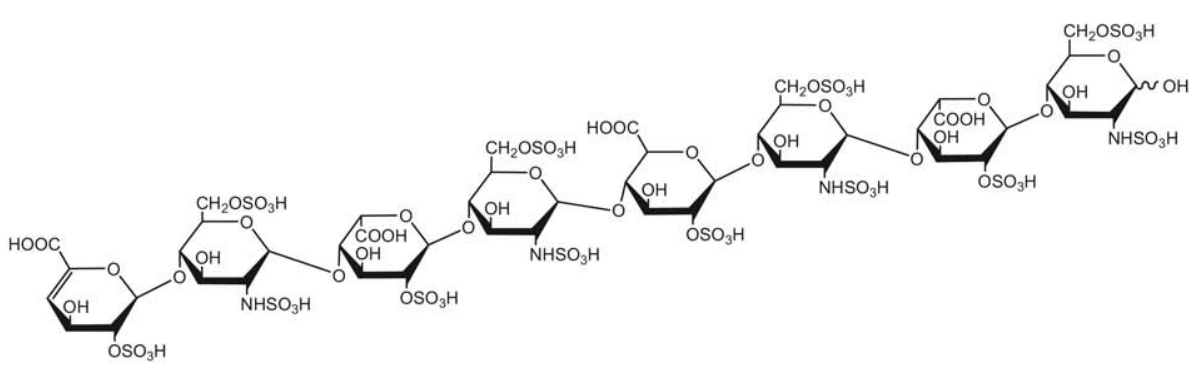

Scheme 1. Structures of the small, polyanionic molecules. (a) Arixtra, (b) sucrose octasulfate, (c) suramin, (d) cyclodextrin sulfate, and (e) fully sulfated heparin octasaccharide, Octa $/ 12 \mathrm{SO}_{3}$.

recently proposed that interfering with the chemokineGAG binding may also be an effective method for targeting chemokine-mediated cell recruitment and inflammation $[3,7,9]$. Since there are significant redundancies in the chemokine system (multiple chemokines bind to the same receptor, and vice versa), a major advantage of this strategy is that a molecule targeting the conserved GAG binding site may circumvent the complication of coordinated cell recruitment by multiple chemokines [10].

Small, anionic molecules have been used to modulate the function of several heparin-binding proteins. In one case, the binding of the dengue virus envelop protein to a highly sulfated form of the cell surface HS is one of the initial steps in infection. It was shown that a small, polyanionic molecule, suramin, could effectively compete off the dengue virus envelope protein bound to heparin immobilized on a microtiter plate, with a potency exceeding soluble heparin. It was also observed that addition of suramin to the culture completely prevented Vero cells from infection by dengue virus [11, 12]. In another example, Arixtra, a small heparin pentasaccharide (Scheme 1a) was shown to bind specifically to antithrombin (AT) [13]. It has a critical 3-O-sulfate [14], which is rare in the natural heparin sequences. It is also modified with $\mathrm{N}-, 2-\mathrm{O}-$, and 6-O-sulfation. The binding of Arixtra induces a conformational change of AT, which significantly potentiates it as an inhibitor of the serine proteases, Factor $\mathrm{Xa}$, and thrombin, involved in blood clot formation [15]. This small pentasaccharide has thus been used medically as an anticoagulant drug. By blocking the interactions of the chemokines with the cell surface GAGs, possibly some small anionic molecules may function as inhibitors of cell recruitment and form the basis of novel therapeutics for pathological immunoresponse.

Several instrumental methods have been established for the characterization of protein/ligand noncovalent complexes, including NMR, X-ray crystallography, surface plasmon resonance (SPR), circular dichroism, light scattering, isothermal titration calorimetry, size-exclusion chromatography/native gel electrophoresis, and fluorescence titration [16, 17]. The more recent characterization of protein/ligand noncovalent complexes by mass spectrometry has been aided by the development of gentle ionization methods (electrospray ionization and matrix-assisted laser desorption/ionization). It has 
been shown that specific noncovalent complexes are observed under finely tuned instrument conditions including, angle of the spraying needle, pressure of the nebulizing/drying gas, capillary heating, and accelerating voltage at the nozzle-skimmer region [17-23]. Once desolvated, the noncovalent complex ions can be analyzed for their molecular weight, binding stoichiometry and relative/absolute binding affinity by mass spectrometry [21]. Indeed, mass spectrometry has been applied to study enzyme-substrate, enzyme-inhibitor, and even intact multimeric protein complexes [24-26]. Compared with other characterization methods, mass spectrometry has key advantages including sensitivity and speed [17].

In this study, we investigate the interaction of two chemokines, MCP-1/CCL2 and MCP-3/CCL7, with a series of small, anionic molecules, with the goal of identifying potential binders. This will facilitate the design of therapeutics for pathological inflammation. Two mass spectrometry based methods were used to characterize these interactions. The first method was a filtration trapping assay, which relies on the use of salt washing with a molecular weight cut-off filter and detection of the retained noncovalent complex. This assay has been successfully used in a previous study to screen for chemokine-binding heparin oligosaccharides and determine their binding stoichiometry using FT-ICR mass spectrometry [22]. The filtration trapping results for the small, anionic molecules were confirmed by a hydrophobic trapping assay in which the chemokine-GAG complex was adsorbed on a hydrophobic column, and the specific ligands were eluted using a high concentration salt wash. These two methods were applied to study the binding of small polyanions (Scheme 1), including Arixtra (fondaparinux sodium), sucrose octasulfate (SOS), suramin, and cyclodextrin sulfate, to the CCR2 ligands MCP-1 and MCP-3.

\section{Experimental}

\section{Materials}

All polymerases and restriction endonucleases were purchased from New England Biolabs (Beverly, MA). Enterokinase was expressed and purified as previously described [27]. Heparinase I (EC 4.2.2.7) was purchased from Calbiochem (La Jolla, CA). The human chemokines MCP-1/CCL2 and MCP-3/CCL7 were expressed and purified as previously described [22]. Suramin and cyclodextrin sulfate were purchased from Sigma (St. Louis, MO). Sucrose octasulfate was obtained from Toronto Research Chemicals (Toronto, Canada). Heparin octasaccharide library was purchased from Dextra Laboratories (Reading, UK). The other small anionic molecules (Arixtra and the fully sulfated heparin octasaccharide) were prepared as described below.

\section{Filtration Trapping Assay}

For the filtration trapping assay, $40 \mu \mathrm{M}$ the target protein was mixed with $200 \mu \mathrm{M}(100 \mu \mathrm{M}$ for suramin) of the ligand in $100 \mu \mathrm{l}$ of $100 \mathrm{mM} \mathrm{NH}_{4} \mathrm{OAc}(\mathrm{pH}$ 6.8) at room temperature. The solution was loaded onto a centrifugal ultrafiltration unit with a molecular weight cutoff of $10 \mathrm{kDa}$ (Millipore, Billerica, MA) and subjected to three times centrifugation (5000 rpm; $40 \mathrm{~min} ; 4^{\circ} \mathrm{C}$ ), each using $1 \mathrm{ml} 200 \mathrm{mM} \mathrm{NH}{ }_{4} \mathrm{OAc}(\mathrm{pH}$ 6.8) as the washing buffer. The retentate $(\sim 50 \mu \mathrm{l})$ was diluted by addition of 1 volume of water and analyzed by ESI FT-ICR mass spectrometry.

\section{Hydrophobic Trapping, Elution, and Confirmation of Bound Ligands}

For the hydrophobic trapping assay, $40 \mu \mathrm{M}$ target protein was incubated with $200 \mu \mathrm{M}$ the ligand in $100 \mu \mathrm{l}$ of $100 \mathrm{mM} \mathrm{NH}_{4} \mathrm{OAc}$ solution ( $\mathrm{pH}$ 6.8). The solution was applied to an Oasis solid-phase extraction (SPE) cartridge (Waters, Milford, MA) that had been previously conditioned using $1 \mathrm{ml}$ of methanol and then $1 \mathrm{ml}$ of $\mathrm{H}_{2} \mathrm{O}$. The solid-phase SPE cartridge was flushed three times, each using $1 \mathrm{ml} 200 \mathrm{mM} \mathrm{NH}_{4} \mathrm{OAc}$ solution ( $\mathrm{pH}$ 6.8) and then eluted by $1 \mathrm{ml} 760 \mathrm{mM} \mathrm{NH}_{4} \mathrm{OAc}(\mathrm{pH}$ 6.8). The eluate was desalted by extensive lyophilization or by dialyzing against water using a dialyzer with a molecular weight cutoff (MWCO) of $1 \mathrm{kDa}$ (The Nest Group, Southborough, MA).

\section{Fourier Transform Ion Cyclotron (FT-ICR) Mass Spectrometry}

Mass spectra were acquired on a Bruker APEX II 7-tesla FT-ICR mass spectrometer (Bruker, Billerica, MA), which was equipped with an Apollo (Bruker) electrospray ion source. The noncovalent complex ions were generated as previously described [21,22]. Samples were infused into the mass spectrometer at 1 $\mu \mathrm{l} / \mathrm{min}$ using a syringe pump (Harvard Apparatus, Holliston, MA). Nitrogen at 50 psi was used as the nebulizing gas. The capillary exit voltage was adjusted to $140 \mathrm{~V}$ (positive mode) or $40 \mathrm{~V}$ (negative mode) for ion desolvation. Ions were externally accumulated in a radio frequency-only hexapole for $0.5 \mathrm{~s}$ before transfer into the ICR cell for mass analysis. Ions were trapped using gated trapping and detected after chirp excitation. Between 8 and 100 broadband time domain transients containing $512 \mathrm{k}$ or $1024 \mathrm{k}$ data points were averaged before zerofill, Gaussianmultiplication, and fast Fourier transform. The parameters of the ESI source, ion optics, and cell were optimized for the best ion intensity. All the data were acquired and processed using Xmass v 6.0.0 (Bruker, Billerica, MA). 


\section{Isolation of Heparin Octasaccharide Modified with 12 Sulfates $\left(\mathrm{Octa} / 12 \mathrm{SO}_{3}\right)$}

Heparin octasaccharide modified with 12 sulfates (Octa $/ 12 \mathrm{SO}_{3}$, Scheme 1e) was isolated from the heparin octasaccharide mixture by using strong anion-exchange HPLC (SAX HPLC). Approximately $400 \mu \mathrm{g}$ of the octasaccharide library was injected onto a CarboPac PA1 column (Dionex, Sunnyvale, CA) and SAX HPLC (Waters, Milford, MA) was performed at a flow rate of $1 \mathrm{ml} / \mathrm{min}$ using Solvent A $\left(\mathrm{H}_{2} \mathrm{O}, \mathrm{pH}\right.$ 3.5) and Solvent B (3 M NaCl, pH 3.5). A typical gradient consisted of: (1) 1-11 $\mathrm{min}, 0 \% \mathrm{~B}$, (2) $11-110 \mathrm{~min}, 0-100 \% \mathrm{~B}$, and (3) 111-120 min, 0\% B. Chromatograms were recorded by monitoring the UV absorbance at $232 \mathrm{~nm}$ [28]. Fractions corresponding to Octa/12 $\mathrm{SO}_{3}$ were collected, lyophilized, and desalted.

\section{Sample Preparation for Arixtra}

Arixtra (fondaparinux sodium) was purchased from GlaxoSmithKline (Research Triangle Park, NC). It was subsequently desalted in preparation for mass spectrometric $K_{d}$ measurements. One hundred microliters of $2.9 \mathrm{mM}$ Arixtra solution was dialyzed against water for 3 to 4 days. The process of desalting was monitored by ESI FT-ICR mass spectrometry. An enzyme-coupled UV assay was used to determine the concentration of the desalted Arixtra. Arixtra is susceptible to heparinase I cleavage, which yields an unsaturated disaccharide (containing the original reducing end) and a trisaccharide (containing the original non-reducing end). The enzymatically generated double-bond on the disaccharide has a strong absorbance at $232 \mathrm{~nm}$ [28], and thus the concentration of the disaccharide was determined and correlated 1:1 to the original concentration of Arixtra.

Digestion was performed in a $100 \mu \mathrm{l}$ solution of 20 $\mathrm{mM}$ Tris- $\mathrm{HCl}$ (pH 7.4), $1 \mathrm{mM} \mathrm{CaCl} 2,3 \mathrm{mU}$ heparinase I, and $2 \mu \mathrm{l}$ Arixtra at RT. The reaction was initiated by addition of the enzyme and was continuously monitored by UV absorption. The concentration of Arixtra was calculated from the increase in the absorption at $232 \mathrm{~nm}$, using a molar extinction coefficient of 3800 $\mathrm{M}^{-1} \mathrm{~cm}^{-1}$ [29].

\section{Dissociation Constant Determination by ESI FT-ICR Mass Spectrometry}

A titration experiment was employed for the MS dissociation constant determination [30, 31]. The MCP-3 concentration was maintained at $10 \mu \mathrm{M}$ and Arixtra was added at the following concentrations: $0.58,1.16$, $1.74,2.32,2.89,4.34,7.24,14.5,21.7$, and $36.2 \mu \mathrm{M}$. The resulting solution was analyzed by ESI FT-ICR mass spectrometry. Assuming a similar ionization efficiency for MCP-3 and the MCP-3/Arixtra noncovalent complex, the peak intensities directly correlated with the solution concentrations and were used to calculate the average number of occupied binding sites on the protein, $\mathrm{V}$, by using the following equation [32]:

$$
V=\frac{[\text { Arixtra }]_{\text {bound }}}{[\text { protein }]_{\text {bound }}}=\frac{\sum I_{M C P-3 / \text { Arixtra }}}{\sum I_{M C P-3}+\sum I_{M C P-3 / A r i x t r a}}
$$

Using the total protein concentration of $10 \mu \mathrm{M}$, the concentration of free Arixtra was calculated using the following equation:

$$
[\text { Arixtra }]_{\text {free }}=[\text { Arixtra }]_{\text {total }}-10 * \mathrm{~V}
$$

The calculated $\mathrm{V}$ and [Arixtra] $]_{\text {free }}$ from different concentration points of Arixtra analyzed were then fit (GraFit version 4.0.12, Horley, Surrey, UK) into eq 3 [32] to calculate the dissociation constant, $K_{d}$, and the number of binding sites, $n$.

$$
V=\frac{n^{*}[\text { Arixtra }]_{\text {free }}}{K_{d}+[\text { Arixtra }]_{\text {free }}}
$$

\section{Dissociation Constant Determination by Isothermal} Titration Calorimetry (ITC)

For all ITC experiments, $1 \mathrm{mM}$ Arixtra was titrated into a $50 \mu \mathrm{M}$ solution of $\mathrm{MCP}-3$ in $10 \mathrm{mM}$ potassium phosphate (pH 7.5), $100 \mathrm{mM} \mathrm{NaCl}$ in water. All experiments were conducted at $25^{\circ} \mathrm{C}$. Titration of Arixtra into MCP-3 was 1 injection of $1 \mu \mathrm{l}$, followed by 52 injections of $5.999 \mu \mathrm{l}$, with a $60 \mathrm{~s}$ initial delay and $250 \mathrm{~s}$ between injections. Heats of injection were recorded using the MCS-ITC (MicroCal, Northampton, MA) and processed using Origin version 2.9 (OriginLab, Northampton, MA), which reported the $K_{d}, \Delta \mathrm{H}$, and $n$ (number of binding sites) of the chemokine-Arixtra interaction.

\section{Results and Discussion}

We have demonstrated that ESI FT-ICR mass spectrometry is a valuable tool to study protein-ligand interactions [21-23, 33, 34]. In combination with a filtration trapping assay, it was used for the screening of heparin oligosaccharide ligands of chemokines [22]. In addition to ligand identification, this label-free screening methodology also allows for determination of the proteinligand binding stoichiometry [17]. As a complementary method, a hydrophobic trapping assay was used to confirm the results obtained from the filtration trapping assay. We have extended the current MS methodologies to study the binding between chemokines and a series of small polyanions, including Arixtra, suramin, SOS, and cyclodextrin sulfate (Scheme 1), with the goal of identifying possible chemokine binding molecules that may potentially function as competitive inhibitors of chemokine-GAG interactions. 


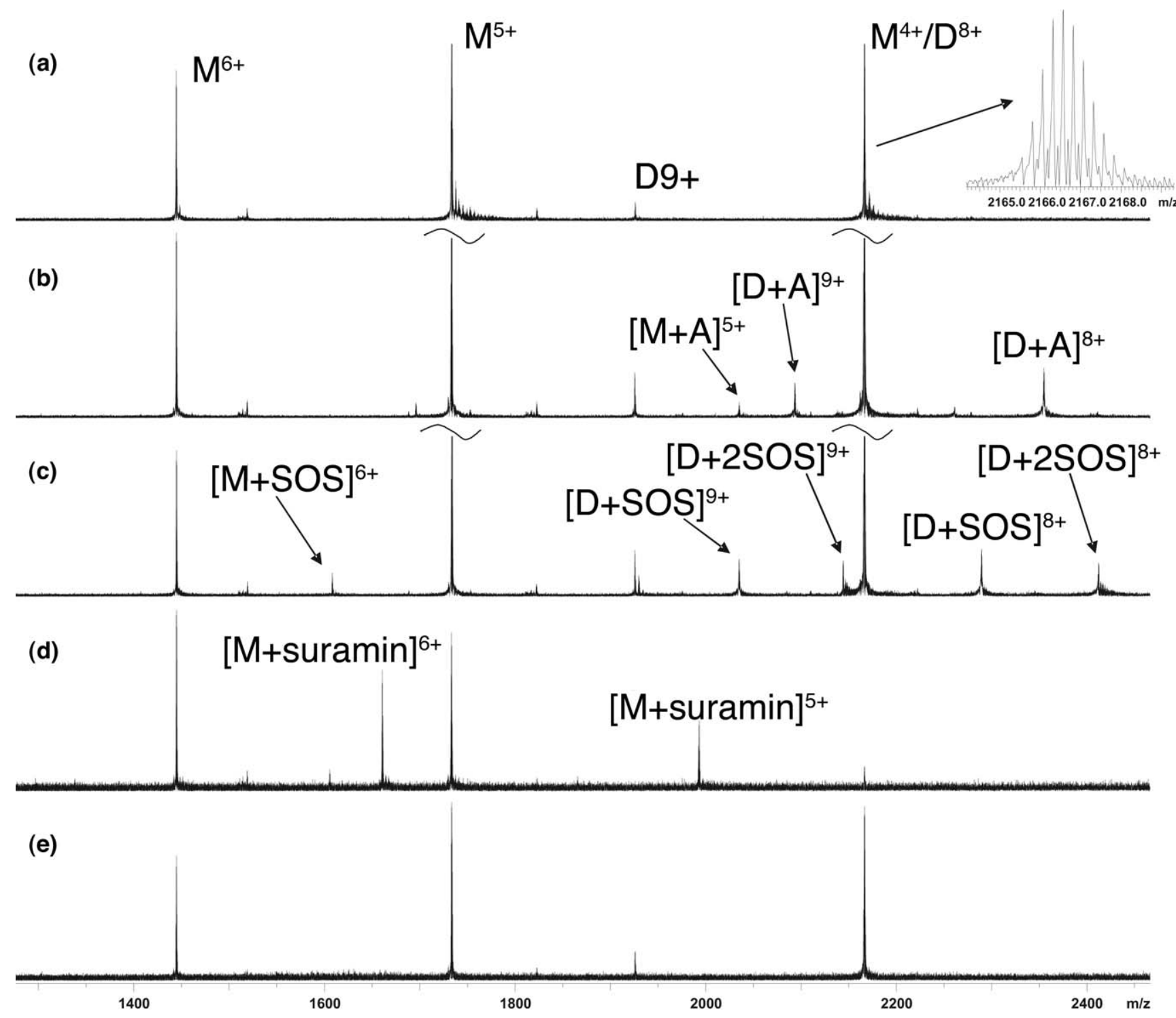

Figure 1. ESI mass spectra of (a) $5 \mu \mathrm{M}$ MCP-1 sprayed from $100 \mathrm{mM} \mathrm{NH}_{4} \mathrm{OAc}$ ( $\mathrm{pH}$ 6.8). Inset, the isotopic distribution of the ions at $\mathrm{m} / \mathrm{z} 2166$. The dimer ions (8+) were clearly resolved as the lower isotopic distribution, and (b-e) filtration trapping assay of the small polyanionic molecules against MCP-1. (b) Arixtra. [M + A], MCP-1 monomer in complex with Arixtra; [D + A], MCP-1 dimer in complex with Arixtra. (c) Sucrose octasulfate (SOS), (d) suramin, and (e) cyclodextrin sulfate.

Filtration Trapping Analysis to Identify MCP-1/ Small Molecule Complexes

As shown in Figure 1a, wild type MCP-1 was initially analyzed by spraying from a solution of $100 \mathrm{mM}$ $\mathrm{NH}_{4} \mathrm{OAc}$. Under these conditions, MCP- 1 exists primarily as a monomer in equilibrium with a small amount of dimer. This protein $(40 \mu \mathrm{M})$ was then incubated with $200 \mu \mathrm{M}$ Arixtra and the solution was loaded onto a molecular weight cut-off filter and subjected to the filtration trapping assay. Salt washing using $200 \mathrm{mM}$ $\mathrm{NH}_{4} \mathrm{OAc}$ has been demonstrated to effectively remove the non-specific/low-affinity ligands and the molecules subsequently detected as complexes with the protein are considered specific binders [22]. As shown in Figure
$1 \mathrm{~b}$, ions corresponding to noncovalent complexes between MCP-1 and Arixtra were clearly observed after the $200 \mathrm{mM}$ salt washing. One of the noncovalent complex ions is consistent with a MCP-1 dimer in complex with one Arixtra molecule, appearing at the $8+$ and $9+$ charge states. An ion of low abundance corresponded to the monomer/Arixtra. Although the concentration of Arixtra used was 5-fold that of the chemokine, no monomer/2Arixtra or dimer/3Arixtra complex was observed, indicating that non-specific aggregation did not occur under these outlined conditions.

Arixtra is a specific inhibitor of activated Factor $X$ (Xa) and has been used as an anticoagulant drug to treat deep vein thrombosis [35]. However, the interaction of 
Arixtra with chemokines has not been thoroughly explored. In one study, Arixtra was shown not to bind to a CXC chemokine platelet factor 4 (PF4) [35]. The fact that noncovalent complexes of MCP-1 and Arixtra persisted after the salt wash indicates that Arixtra is a specific ligand of MCP-1. This is the first reported observation of the interaction between Arixtra and a chemokine in vitro. We have shown previously that the highly sulfated heparin octasaccharides bind to MCP-1 dimer, whereas no monomer complexed with the octasaccharide was observed, indicating a preferential binding of the dimer to the oligosaccharides [22]. This is encouraging as it has been shown that complexation of GAG to some chemokines induces oligomerization [3]. However, in the case of Arixtra, both dimer/Arixtra and minor monomer/Arixtra were observed (Figure 1b). This data suggests that a pentasaccharide is likely not large enough to span the entire heparin-binding site on the MCP-1 dimer, resulting in less preferential binding to the MCP-1 dimer compared with a heparin octasaccharide.

Sucrose octasulfate (SOS, Scheme $\mathbf{1 b}$ ) has been shown to bind to many heparin-binding proteins including follistatin [36], fibroblast growth factor (FGF) [37], and hepatocyte growth factor [38]. Noncovalent complex ions were observed (Figure 1c) after a mixture containing $40 \mu \mathrm{M}$ MCP-1 and $200 \mu \mathrm{M}$ SOS was subjected to the filtration trapping assay. Again, one of the noncovalent complexes observed indicated dimeric formation of MCP-1 with one SOS molecule. Ions corresponding to monomer/SOS and dimer/2SOS were also observed, suggesting a somewhat different binding stoichiometry from that of Arixtra. This interaction is not totally unexpected because of the flexible sugar backbone and its high degree of sulfation (8 sulfates/ molecule).

Although comparable in size with a heparin decasaccharide, suramin contains a hydrophobic core that is flanked by 6 sulfate groups (Scheme 1c) and is structurally different from a heparin oligosaccharide [11]. It has been shown that suramin binds to dengue virus envelope protein, a heparin-binding protein, with an identical affinity compared with heparin [12]. It is also a ligand of aFGF and it has been suggested that the binding site of suramin is located at or near the heparinbinding site on aFGF [39].

Suramin was also investigated as a possible chemokine binder. Our initial attempt to evaluate binding of suramin to MCP-1 was unsuccessful because $200 \mu \mathrm{M}$ suramin caused immediate precipitation of MCP-1. When the concentration of suramin was lowered to 100 $\mu \mathrm{M}$ and mixed with $40 \mu \mathrm{M} \mathrm{MCP}-1$, less aggregation was observed. This solution was subjected to salt wash and analyzed by FT-ICR mass spectrometry. As shown in Figure 1d, the noncovalent complex between MCP-1 and suramin was observed in the mass spectrum. However, in contrast to Arixtra, SOS, or the highly sulfated heparin octasaccharides [22], binding to the monomer is clearly preferred and no MCP-1 dimer in complex with suramin was observed.

Dissociation of multimeric protein complexes upon suramin binding has been observed for several heparinbinding proteins. For example, bFGF alone was found to multimerize in solution. It also forms $2: 1,3: 1$, and $4: 1$ complexes with heparin decasaccharides [40]. However, the binding stoichiometry of bFGF and suramin was found to be 1:1, indicating the dissociation of the oligomers [39]. In another example, the oligomerization state of human tumor necrosis factor $\alpha$ (TNF- $\alpha)$ in the presence of suramin was studied using size-exclusion chromatography. TNF- $\alpha$ exists as a trimer under physiological conditions, and it was shown that suramin promoted TNF- $\alpha$ deoligomerization to monomers and dimers [41]. The dissociation kinetics supports an allosteric model in which the binding of suramin induces a conformation change of the trimeric TNF- $\alpha$ to a state that is more prone to dissociation. However, another model in which suramin simply binds preferentially to the monomer and/or dimer can not be ruled out. In the case of MCP-1, the mass spectrometric binding data of suramin is in accordance with either of these two models. In one instance, the binding of suramin to MCP-1 dimer might be transient, which results in the rapid dissociation of the dimeric complex and the observation of MCP-1 monomer/suramin. On the other hand, it is also possible that the unique hydrophobic moiety of suramin may interact with the MCP-1 monomer at its dimer interface. This would contribute to the preferential binding of suramin to MCP-1 monomer. These two models cannot be differentiated by the current experimental method, and further structural studies will be needed to determine the exact binding mechanism. However, since the dimer formation is critical for the in vivo function of MCP-1 [42], the binding of suramin to MCP-1 as well as disruption of the dimer by the binding may be indicative of a potential inhibitory effect on MCP-1.

Cyclodextrin sulfate (Scheme 1d) has the highest degree of sulfation (average of $14 \sim 15$ sulfate per molecule) amongst the molecules investigated. However, it showed no binding to MCP-1 after the salt wash using $200 \mathrm{mM} \mathrm{NH}_{4} \mathrm{OAc}$ (Figure 1e). Previously, Rusnati et al. showed in a competition assay that cyclodextrin sulfate was not able to displace heparin from immobilized HIV TAT protein even at concentrations as high as $300 \mu \mathrm{M}$ [43]. In agreement with its inability to affect the TAT/ heparin interaction $[43,44]$, cyclodextrin sulfate showed no binding to MCP-1. These data suggest that a linear, flexible backbone structure may be a critical determinant for ligand binding to MCP-1.

\section{Hydrophobic Trapping Analysis of the MCP-1/ Small Molecule Complexes}

The results of the filtration trapping were confirmed using the hydrophobic trapping assay. This method 
Arixtra

(a)

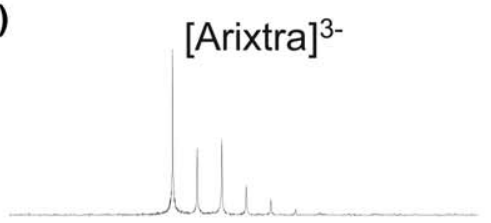

(b)

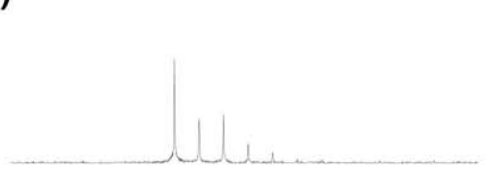

SucroseOctasulfate

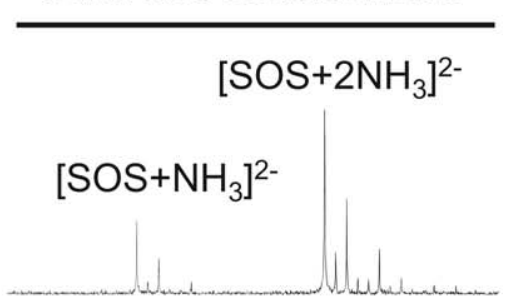

Cyclodextrin sulfate

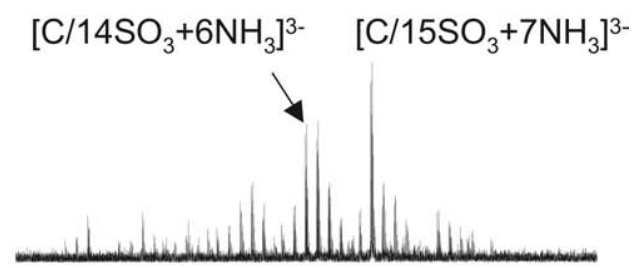

(c)

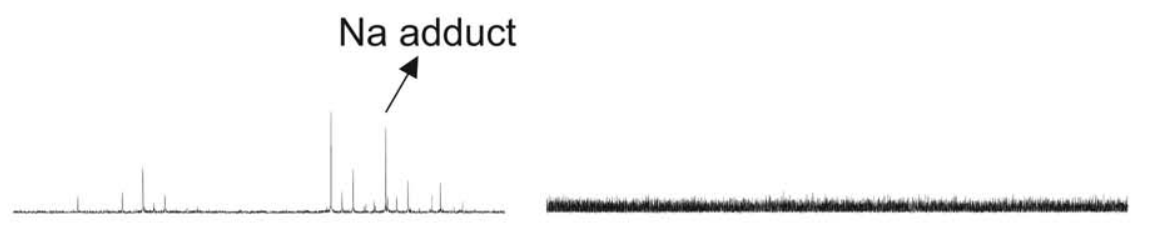

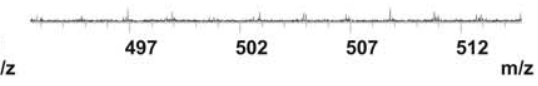

Figure 2. Hydrophobic trapping assay of the small polyanionic molecules against MCP-1. The fractions were desalted and sprayed from a solvent of 50:50 MeOH:H $\mathrm{H}_{2} \mathrm{O}$ with $10 \mathrm{mM} \mathrm{NH}_{4} \mathrm{OH}$. (a) The small molecule standards, (b) the $760 \mathrm{mM} \mathrm{NH}_{4} \mathrm{OAc}$ elution fraction, and (c) the elution fractions of the control experiments in which only the small molecule was loaded on the column, washed with 200 $\mathrm{mM} \mathrm{NH}_{4} \mathrm{OAc}$ and eluted with $760 \mathrm{mM} \mathrm{NH} \mathrm{m}_{4} \mathrm{OAc}$. C/14SO $\mathrm{S}_{3}$, cyclodextrin sulfate modified with 14 sulfates. Additional smaller ions represent ammonium and sodium adducts.

makes use of the hydrophobicity difference between the protein/protein complexes and small anionic molecules. The target protein was incubated with the ligand and then the solution was passed through a reverse phase SPE cartridge. Proteins and protein/ligand complexes are retained on the column and the non-specific binders are removed by $200 \mathrm{mM}$ salt washes. The high-affinity binders are eluted by a salt wash using 760 $\mathrm{mM} \mathrm{NH}{ }_{4} \mathrm{OAc}$.

This method was applied to test the binding of the polysulfated molecules to chemokines. In three parallel experiments, $40 \mu \mathrm{M} \mathrm{MCP}-1$ was incubated with Arixtra, SOS, or cyclodextrin sulfate, each at a concentration of $200 \mu \mathrm{M}$. Suramin was not tested because it is more hydrophobic and binds strongly to the reverse-phase SPE cartridge. Both Arixtra and sucrose octasulfate were observed in the $760 \mathrm{mM}$ salt elute fraction, clearly indicating that they are specific binders of MCP-1 (Figure 2b). They were not observed in the high salt elution fraction of the control experiment, in which only the small molecule alone was loaded onto the column (Figure 2c), indicating the absence of non-specific binding to the SPE cartridge. In contrast, cyclodextrin sulfate did not bind to MCP-1. These data were in complete accordance with the results of the filtration trapping assay. This data also clearly indicates that binding is not due to pure electrostatic interactions as cyclodex- trin sulfate was the most negatively charged molecule chosen.

\section{Filtration/Hydrophobic Trapping Analysis of the Binding of Small Molecules to MCP-3}

Both the filtration trapping and hydrophobic trapping experiments were then repeated on the binding between MCP-3 and the small anionic molecules. The spectrum of MCP-3 from a solution of $100 \mathrm{mM} \mathrm{NH}_{4} \mathrm{OAc}$ $(\mathrm{pH}$ 6.8) is shown in Figure 3a. In contrast to MCP-1, which exists in equilibrium between monomer and dimer, only monomeric MCP-3 was observed.

Arixtra, suramin, and SOS were all observed to bind to MCP-3, albeit MCP-3/SOS was observed at a very low abundance (Figure 3). A binding stoichiometry of 1:1 was observed for all these ligands, indicating that polyanionic molecules do not induce multimerization of MCP-3. Cyclodextrin sulfate showed no binding to MCP-3, suggesting that it is also not a ligand of this chemokine.

The results of the filtration trapping assay were then verified with Arixtra, SOS, or cyclodextrin sulfate and MCP-3 by using the hydrophobic trapping assay. As shown in Figure 4, Arixtra and SOS were observed in the high salt elution fraction and not in the control experiment, indicating that they are specific ligands of 

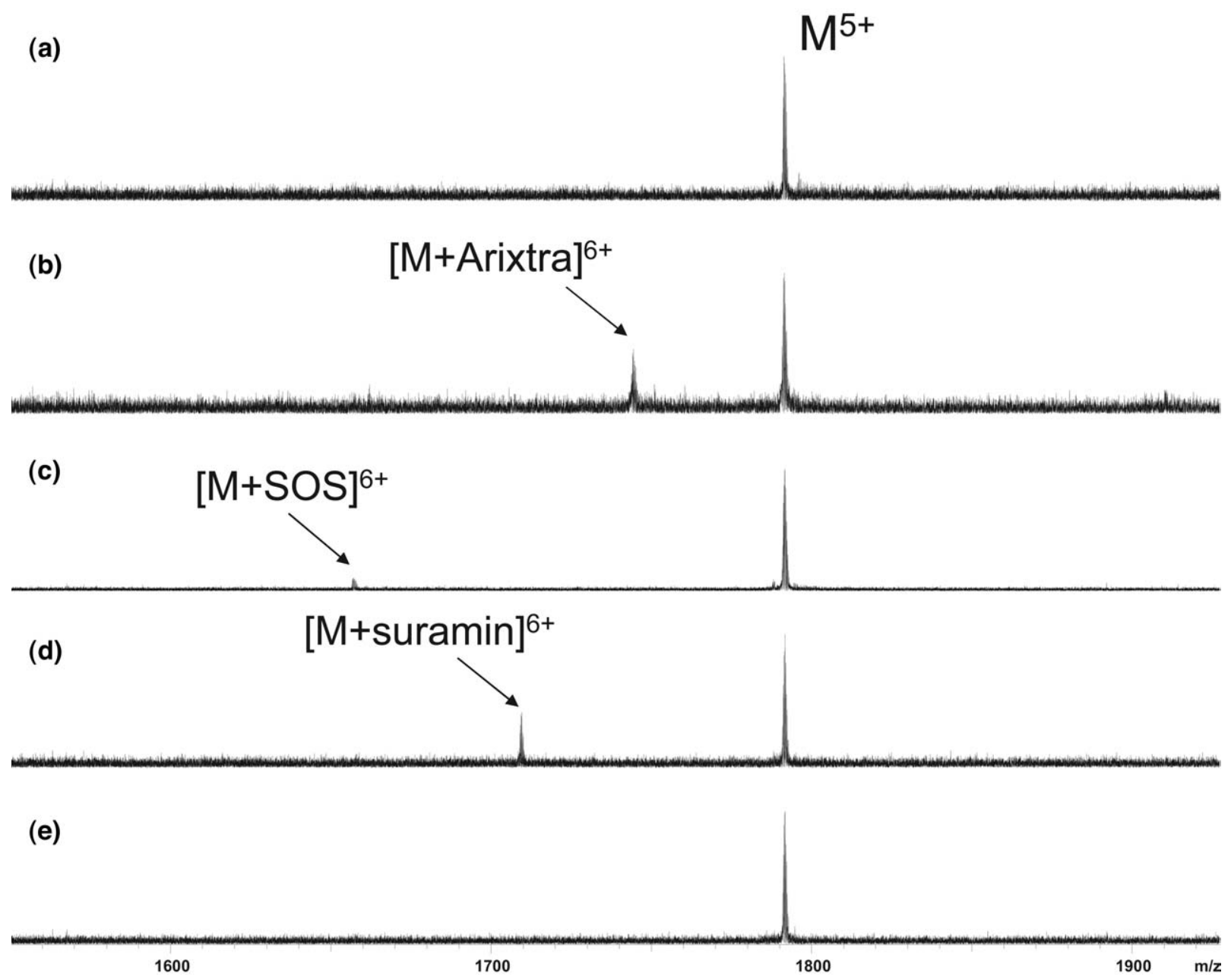

Figure 3. ESI mass spectra of (a) $5 \mu \mathrm{M} \mathrm{MCP-3} \mathrm{sprayed} \mathrm{from} 100 \mathrm{mM} \mathrm{NH}_{4} \mathrm{OAc}(\mathrm{pH}$ 6.8), and (b-e) filtration trapping assay of the small polyanionic molecules against MCP-3. (b) Arixtra, (c) sucrose octasulfate, (d) suramin, and (e) cyclodextrin sulfate.

MCP-3. Again, no cyclodextrin sulfate was observed in the eluate. The results of the hydrophobic trapping assay were again in complete agreement with those of the filtration trapping assay.

\section{$K_{d}$ Determination by ESI FT-ICR Mass Spectrometry}

Traditionally, the dissociation constant of a protein/ ligand noncovalent complex can be determined by several methods, including surface plasmon resonance (SPR), non-denaturing gel electrophoresis, and fluorescence titration [16, 17]. For example, the interactions between chemokines and sulfated glycosphingolipids (sulfatides) were studied using SPR [45]. It was observed that various chemokines including MCP-1/ CCL2, IL-8/CXCL8, SDF-1 $\alpha /$ CXCL12, MIP-1 $\alpha$ /CCL3, and MIP-1 $\beta /$ CCL4 showed binding to sulfated glycosphingolipids, but not to gangliosides, neutral glycosphingolipids, or phospholipids. However, these methods have some limitations. SPR requires the immobilization of either the ligand or the protein on solid matrices, which may affect the binding properties due to distortion of the binding site. The determination of the binding stoichiometry by chromatographic methods depends on the elution or the mobility times, which are sensitive to the shape and physical properties of the protein. Thus, it is more affected by the calibrant proteins [17].

Utilizing mass spectrometry, the protein and protein/ligand complex can be detected simultaneously. Thus, ESI-MS can be used to determine the dissociation constant for some protein-ligand complexes. One caveat to this method is that the ratio of the protein and protein/ligand complex must not change during the transfer from solution into the gas-phase [21]. Possibly, dissociation of the complexes or non-specific aggregation occurs during the ESI process. This results in an inaccurate reflection of the solution concentrations of the solution noncovalent complexes. For example, the binding of rapamycin analogs to FKBP (FK506 binding protein) has been studied using ESI-MS and ESIMS/MS experiments [46]. Since the binding is largely driven by hydrophobic effects, which diminish in the 

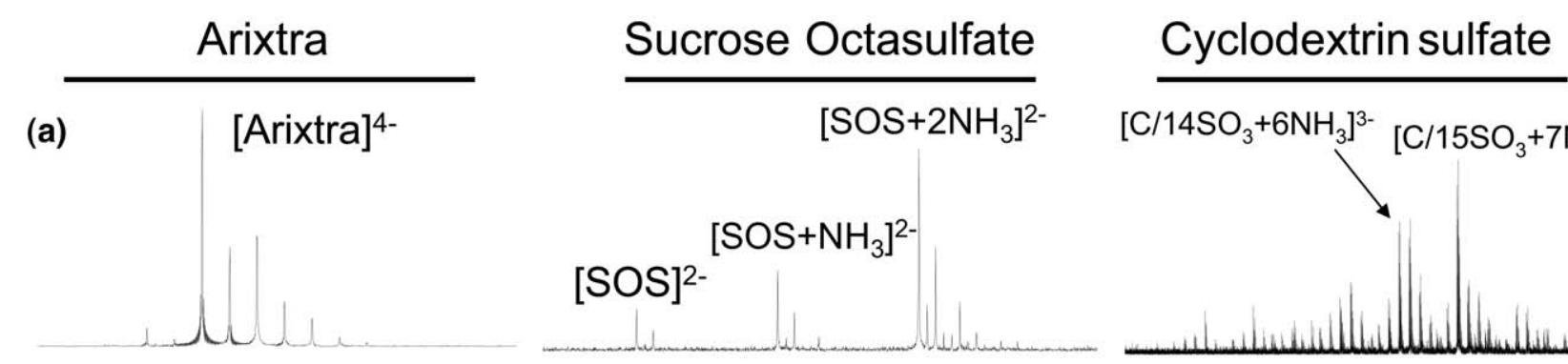

(b)
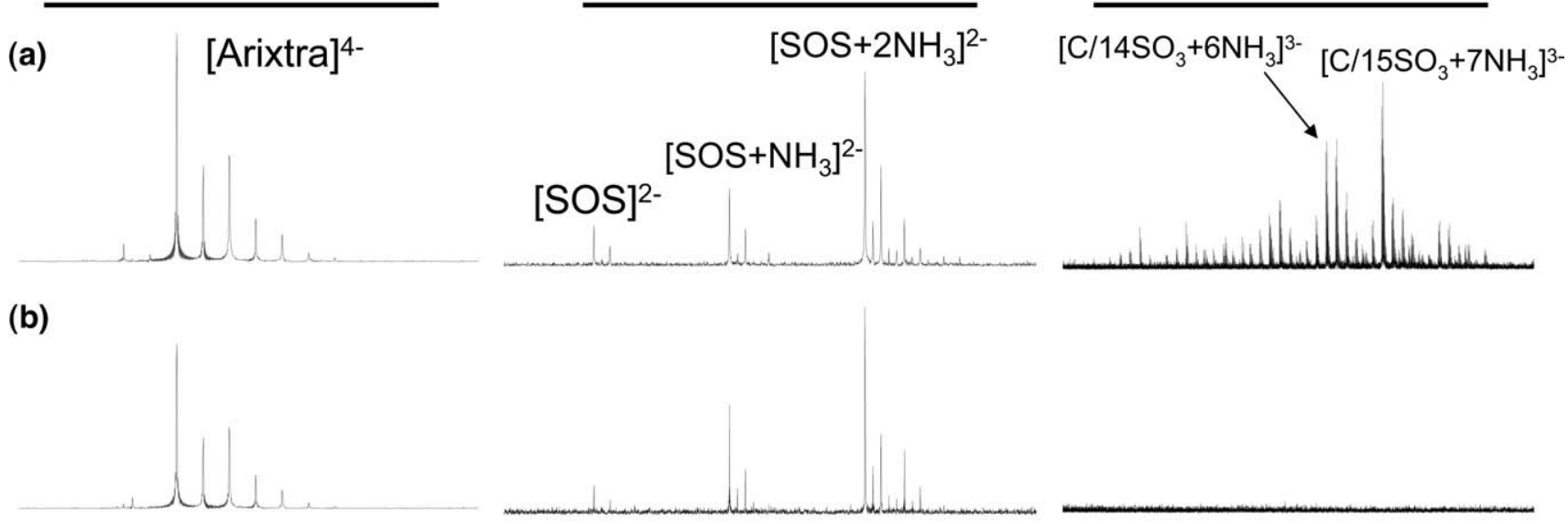

(c)

375.0

$\begin{array}{lll}376.0 & 377.0 & 378.0 \mathrm{~m} / \mathrm{z}\end{array}$

490

500

510

$\mathrm{m} / \mathrm{z}$

680

730

780

$830 \quad 880 \mathrm{~m}$

Figure 4. Hydrophobic trapping assay of the small polyanionic molecules against MCP-3. The fractions were desalted and sprayed from a solvent of 50:50 MeOH: $\mathrm{H}_{2} \mathrm{O}$ with $10 \mathrm{mM} \mathrm{NH} \mathrm{mH}_{4} \mathrm{O}$. (a) The small molecule standards, (b) the $760 \mathrm{mM} \mathrm{NH}_{4} \mathrm{OAc}$ elution fractions, and (c) the elution fractions of the control experiments in which only the small molecule was loaded on the column, washed with 200 $\mathrm{mM} \mathrm{NH} \mathrm{NH}_{4} \mathrm{OAc}$ and eluted with $760 \mathrm{mM} \mathrm{NH} \mathrm{OAc}_{4} \mathrm{C} / 14 \mathrm{SO}_{3}$, cyclodextrin sulfate modified with 14 sulfates. Additional smaller ions represent ammonium and sodium adducts.

gas-phase, the relative abundance of the complexes did not correlate with the solution affinities. However, for complexes composed of hydrogen bonding and electrostatic interactions, there are several examples in which the solution binding affinities can be accurately reflected by the gas-phase data. This observation is largely the result of the absence of "solvent screening" in the gas-phase, which strengthens the ionic interactions and prevents the complex from dissociating, thus allowing the investigator to conduct titration experiments. For example, the relative and absolute dissociation constants have been determined using ESI MS for the NodH sulfotransferase [21] and Src SH2 domain protein [31] systems, and the results compared favorably with those of the solution characterization based method.

Since the chemokine-GAG interaction is highly electrostatic, we performed an MS determination of the dissociation constant for the complex between MCP-3 and Arixtra. The dissociation constant of Arixtra for MCP-3 was measured by maintaining the concentration of MCP-3 at $10 \mu \mathrm{M}$ and titrating Arixtra from 0.58 to $36.2 \mu \mathrm{M}$. The resulting mixture was analyzed directly by ESI FT-ICR mass spectrometry. Only a 1:1 complex formed between MCP-3 and Arixtra under these conditions. Because the molecular weight of Arixtra is relatively small compared with that of MCP-3 (16.8\%), it is assumed that MCP-3 and MCP-3/Arixtra have similar ionization efficiencies. Therefore, the measured ion intensities in the mass spectra were used to calculate their concentrations in solution. The average number of occupied binding sites on the protein, $\mathrm{V}$, was calculated using eq 1 . In this equation, $\mathrm{I}_{\mathrm{MCP}-3}$ corresponded to the ion intensities of free $\mathrm{MCP}-3$ and $\mathrm{I}_{\mathrm{MCP}-3 / \text { Arixtra corre- }}$ sponded to those of the MCP-3/Arixtra complexes. Since the total MCP-3 concentration is $10 \mu \mathrm{M}$, the free Arixtra concentration, [Arixtra] $]_{\text {free, }}$ was calculated by using eq 2. From this, $\mathrm{V}$ and [Arixtra] $]_{\text {free }}$ were fit into eq 3 to derive the dissociation constant (Figure 5a). Based on three replicate experiments, the dissociation constant between MCP-3 and Arixtra was determined to be 7.7 $\pm 1.1 \mu \mathrm{M}$.

The number of binding sites, $n$ (calculated from eq 3 ), of MCP-3 is $\sim 0.23$, whereas the binding stoichiometry observed for the MCP-3/Arixtra noncovalent complex is $1: 1$. This discrepancy indicates that saturation of the protein was not reached in the Arixtra titration experiment. One reason for the unsaturation was the suppression of ionization of the protein, and especially the protein/Arixtra complex. A gradual decrease in the ion intensities was observed when increasing concentrations of Arixtra were titrated (data not shown). The calculation of the number of binding sites is more affected because it was calculated from the data points at higher Arixtra concentrations. However, the data for lower concentrations of Arixtra were less affected by 

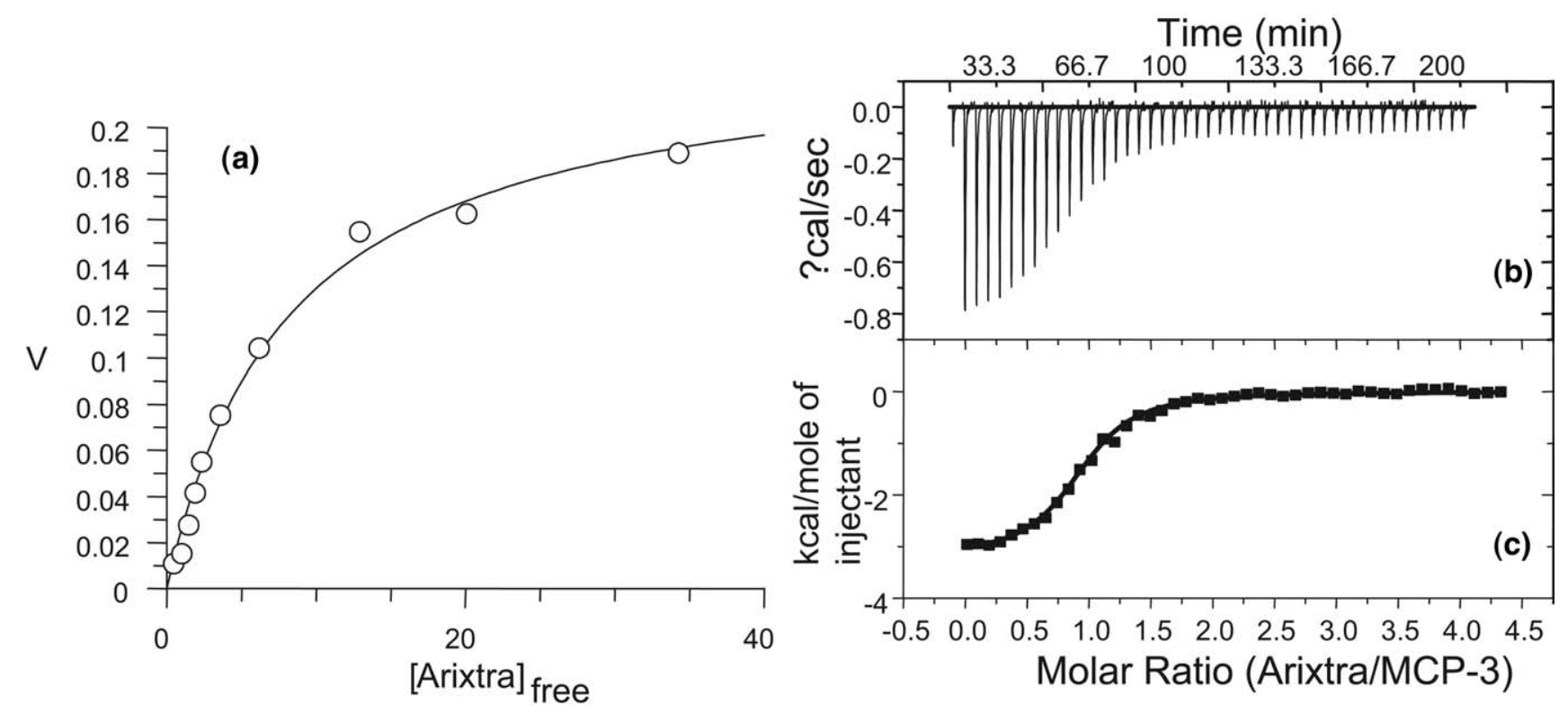

Figure 5. Dissociation constant determination for Arixtra binding to MCP-3. (a) Binding curve obtained from mass spectrometric analysis. Titration experiments were performed in three replicate experiments and one representative binding curve is shown. Various concentrations of Arixtra were titrated into a $10 \mu \mathrm{M}$ MCP-3 in $100 \mathrm{mM} \mathrm{NH}_{4} \mathrm{OAc}$. The resulting solution was analyzed by ESI FT-ICR mass spectrometry. The average number of the occupied binding sites on the protein, $\mathrm{V}$, and the free Arixtra concentration, [Arixtra] $]_{\text {free }}$ were fitted into eq 3 to calculate the dissociation constant. (b) ITC titration experiment and a representative binding curve, (c). For ITC experiments, $1 \mathrm{mM}$ Arixtra was titrated into a $50 \mu \mathrm{M}$ solution of MCP-3. The solvent was $10 \mathrm{mM}$ potassium phosphate at $\mathrm{pH} 7.5,100$ $\mathrm{mM} \mathrm{NaCl}$ in water.

this issue and a reasonable estimation of the dissociation constant could be obtained (see below for a comparison with the ITC data).

\section{Dissociation Constant Determination by Isothermal Titration Calorimetry (ITC)}

Isothermal titration calorimetry is a well established method for studying protein-ligand interactions. This method allows determination of binding constants $\left(K_{d}\right)$, heats of binding $(\Delta \mathrm{H})$, and the apparent number of binding sites (n). The advantages of ITC include the relative ease of analysis, the ability to determine thermodynamic parameters directly, and accurate determination of dissociation constants over a wide range of affinities (millimolar-nanomolar). Unfortunately, ITC requires large quantities of sample, and is somewhat time intensive. In this study, ITC was an ideal solution phase technique to use as a check on the mass spectrometric $K_{d}$ determination. Isothermal titration calorimetry requires no immobilization of chemokine or GAG and can accurately measure the fairly weak chemokineGAG interactions. Based on three replicate experiments, the dissociation constant of MCP-3 and Arixtra was determined to be $3.5 \pm 1.2 \mu \mathrm{M}$ (Figure $5 \mathrm{~b}$ and $\mathrm{c}$ ). Although two different buffer systems were used in the MS and ITC experiments, the corresponding dissociation constant was in good agreement, validating the use of electrospray FT-ICR in this particular case. The number of binding sites was determined to be $0.9 \pm$ 0.03, indicating MCP-3 forms a 1:1 complex with Arixtra. In addition, the ITC data also indicates that the interaction between MCP-3 and Arixtra is an exothermal reaction with a $\Delta \mathrm{H}$ of $-3172 \pm 86 \mathrm{cal} / \mathrm{mol}$.

\section{Determination of the Relative Order of Binding Affinities}

A competitive filtration trapping experiment was performed in which the protein concentration was less than the total ligand concentration [31]. Arixtra, SOS, and suramin, each at a concentration of $100 \mu \mathrm{M}$, were mixed with $40 \mu \mathrm{M}$ MCP-3. One hundred micromolar Octa/ $12 \mathrm{SO}_{3}$, a known heparin octasaccharide ligand [22] of MCP-3, was also added. After three washings with 200 $\mathrm{mM} \mathrm{NH} \mathrm{NH}_{4} \mathrm{OAc}$, the resulting solution was subjected to ESI FT-ICR mass spectrometric analysis. Although the same initial concentrations were used for these ligands, different ion intensities were observed for the MCP-3 noncovalent complexes after washing (Figure 6). The MCP-3 in complex with Octa $/ 12 \mathrm{SO}_{3}$ is the most abundant noncovalent complex ion, indicating Octa $/ 12 \mathrm{SO}_{3}$ is the tightest binder. Less intense noncovalent complex ions were also observed for suramin and Arixtra. Interestingly, although suramin is not a heparin oligosaccharide, the ion corresponding to its noncovalent complex with MCP-3 is more abundant than that of Arixtra. This indicates that suramin has a reasonable binding affinity 


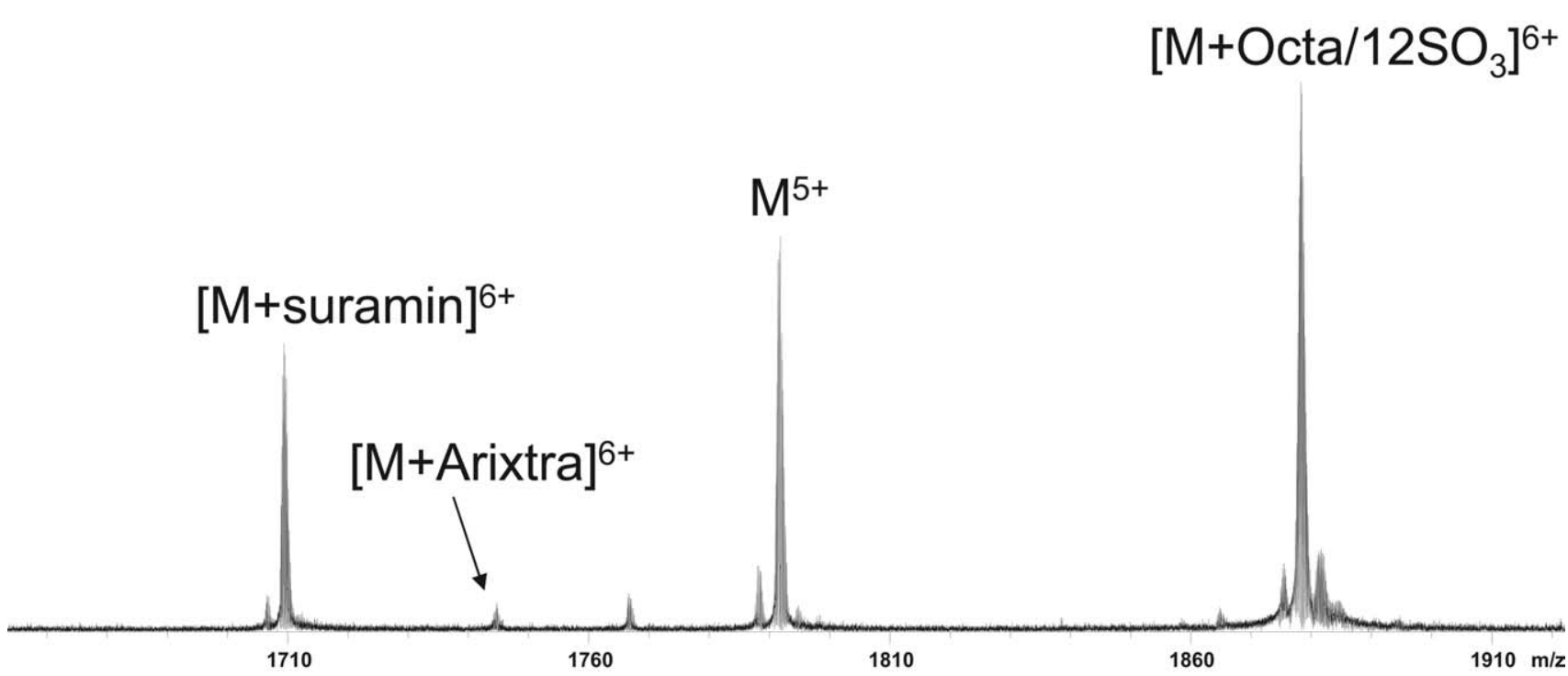

Figure 6. Competitive filtration trapping assay of small anionic molecules binding to MCP-3.

for MCP-3, even if the mode of binding is different from that of Arixtra and SOS. No obvious SOS complex was observed in the competitive binding assay. This is not surprising, considering only very minor complexes were observed when SOS alone was incubated with MCP-3 and subjected to the salt wash. Thus, the competitive binding assay clearly indicates that the relative order of the binding affinities for the molecules studied with MCP-3 is: Octa $/ 12 \mathrm{SO}_{3}>$ Suramin $>$ Arixtra $>$ sOS.

\section{Conclusions}

The binding of a series of small, polyanionic molecules to chemokines has been investigated using a mass spectrometry based filtration trapping assay. Arixtra (an anticoagulant drug) and SOS were observed to bind to chemokines MCP-1 and MCP-3, while cyclodextrin sulfate, although the most sulfated molecule, showed no binding. This indicates that a flexible backbone structure may be an important determinant for ligand binding to chemokines. These results were confirmed by an independent hydrophobic trapping assay. In addition, suramin, a polysulfated binaphthyl urea, was shown for the first time to bind to these two chemokines. The dissociation constant of MCP-3 and Arixtra was determined to be $7.7 \mu \mathrm{M}$ using ESI FT-ICR mass spectrometry, which compared favorably with the value determined using ITC experiments $(3.5 \mu \mathrm{M})$. This indicates that mass spectrometry can be used as a complementary method to determine the binding affinities in such noncovalent complexes. Additionally, the relative binding order of the ligands to $\mathrm{MCP}-3$ was determined as follows: Octa $/ 12 \mathrm{SO}_{3}>$ Suramin $>$ Arixtra $>$ SOS.

\section{Acknowledgments}

The authors acknowledge the NIH, (grant GM 63,581) for funding this research. They gratefully acknowledge Professor Tracy Handel and Susan Crown for expression and purification of the MCP-1 and MCP-3 chemokines. They thank Professor Susan Marqusee and Professor David Wemmer for use of the ITC instrument.

\section{References}

1. Rossi, D.; Zlotnik, A. The Biology of Chemokines and Their Receptors. Annu. Rev. Immunol. 2000, 18, 217-243.

2. Baggiolini, M.; Dewald, B.; Moser, B. Human Chemokines: An Update. Annu. Rev. Immunol. 1997, 15, 675-705.

3. Handel, T. M.; Johnson, Z.; Crown, S. E.; Lau, E. K.; Sweeney, M.; Proudfoot, A. E. Regulation of Protein Function by Glycosaminoglycans as Exemplified by Chemokines. Annu. Rev. Biochem. 2005, 74, 385-410.

4. Proudfoot, A. E. I.; Power, C. A.; Rommel, C.; Wells, T. N. C. Strategies for Chemokine Antagonists as Therapeutics. Semin. Immunol. 2003, 15, 57-65.

5. Raman, R.; Sasisekharan, V.; Sasisekharan, R. Structural Insights into Biological Roles of Protein-Glycosaminoglycan Interactions. Chem. Biol. 2005, 12, 267-277.

6. Witt, D. P.; Lander, A. D. Differential Binding of Chemokines to Glycosaminoglycan Subpopulations. Curr. Biol. 1994, 4, 394-400.

7. Johnson, Z.; Kosco-Vilbois, M. H.; Herren, S.; Cirillo, R.; Muzio, V.; Zaratin, P.; Carbonatto, M.; Mack, M.; Smailbegovic, A.; Rose, M.; Lever, R.; Page, C.; Wells, T. N.; Proudfoot, A. E. Interference with HeparinBinding and Oligomerization Creates a Novel Anti-Inflammatory Strategy Targeting the Chemokine System. J. Immunol. 2004, 173, 5776-5785.

8. Wang, L.; Fuster, M.; Sriramarao, P.; Esko, J. D. Endothelial Heparan Sulfate Deficiency Impairs L-Selectin- and Chemokine-Mediated Neutrophil Trafficking During Inflammatory Responses. Nat. Immunol. 2005, 6, 902-910.

9. Lever, R.; Page, C. P. Novel Drug Development Opportunities for Heparin. Nat. Rev. Drug Discov. 2002, 1, 140-148.

10. Kuschert, G. S.; Coulin, F.; Power, C. A.; Proudfoot, A. E.; Hubbard, R. E.; Hoogewerf, A. J.; Wells, T. N. Glycosaminoglycans Interact Selectively with Chemokines and Modulate Receptor Binding and Cellular Responses. Biochemistry 1999, 38, 12959-12968.

11. Chen, Y.; Maguire, T.; Hileman, R. E.; Fromm, J. R.; Esko, J. D.; Linhardt, R. J.; Marks, R. M. Dengue Virus Infectivity Depends on Envelope Protein Binding to Target Cell Heparan Sulfate. Nat. Med. 1997, 3, $866-871$.

12. Marks, R. M.; Lu, H.; Sundaresan, R.; Toida, T.; Suzuki, A.; Imanari, T.; Hernaiz, M. J.; Linhardt, R. J. Probing the Interaction of Dengue Virus Envelope Protein with Heparin: Assessment of GlycosaminoglycanDerived Inhibitors. J. Med. Chem. 2001, 44, 2178-2187.

13. Bourin, M. C.; Lindahl, U. Glycosaminoglycans and the Regulation of Blood-Coagulation. Biochem. J. 1993, 289, 313-330.

14. Linhardt, R. J.; Toida, T. Role of Glycosaminoglycans in Cellular Communication. Acc. Chem. Res. 2004, 37, 431-438. 
15. Jin, L.; Abrahams, J. P.; Skinner, R.; Petitou, M.; Pike, R. N.; Carrell, R. W. The Anticoagulant Activation of Antithrombin by Heparin. Proc. Natl. Acad. Sci. U.S.A. 1997, 94, 14683-14688.

16. Hensley, P. Defining the Structure and Stability of Macromolecular Assemblies in Solution: The Re-emergence of Analytical Ultracentrifugation as a Practical Tool. Structure 1996, 4, 367-373.

17. Loo, J. A. Studying Noncovalent Protein Complexes by Electrospray Ionization Mass Spectrometry. Mass Spectrom. Rev. 1997, 16, 1-23.

18. Smith, R. D.; Bruce, J. E.; Wu, Q. Y.; Lei, Q. P. New Mass Spectrometric Methods for the Study of Noncovalent Associations of Biopolymers. Chem. Soc. Rev. 1997, 26, 191-202.

19. Sobott, F.; Robinson, C. V. Protein Complexes Gain Momentum. Curr. Opin. Struct. Biol. 2002, 12, 729-734.

20. van den Heuvel, R. H.; Heck, A. J. R. Native Protein Mass Spectrometry: From Intact Oligomers to Functional Machineries. Curr. Opin. Chem. Biol. 2004, 8, 519-526.

21. Yu, Y.; Kirkup, C. E.; Pi, N.; Leary, J. A. Characterization of Noncovalent Protein-Ligand Complexes and Associated Enzyme Intermediates of GlcNAc-6-O-Sulfotransferase by Electrospray Ionization FT-ICR Mass Spectrometry. J. Am. Soc. Mass Spectrom. 2004, 15, 1400-1407.

22. Yu, Y.; Sweeney, M. D.; Saad, O. M.; Crown, S. E.; Handel, T. M.; Leary, J. A. Chemokine-Glycosaminoglycan Binding: Specificity for CCR2 Ligand Binding to Highly Sulfated Oligosaccharides Using FT-ICR MS. J. Biol. Chem. 2005, 280, 32200-32208.

23. Gao, H.; Yu, Y.; Leary, J. A. Mechanism and Kinetics of Metalloenzyme Phosphomannose Isomerase: Measurement of Dissociation Constants and Effect of Zinc Binding Using ESI FT-ICR Mass Spectrometry. Anal. Chem. 2005, 77, 5596-5603.

24. Aplin, R. T.; Robinson, C. V.; Schofield, C. J.; Westwood, N. J. Does the Observation of Noncovalent Complexes between Biomolecules by Electrospray-Ionization Mass-Spectrometry Necessarily Reflect Specific Solution Interactions. Chem. Commun. 1994, 20, 2415-2417.

25. Kraunsoe, J. A. E.; Aplin, R. T.; Green, B.; Lowe, G. An Investigation of the Binding of Protein Proteinase Inhibitors to Trypsin by Electrospray Ionization Mass Spectrometry. FEBS Lett. 1996, 396, 108-112.

26. Lightwahl, K. J.; Schwartz, B. L.; Smith, R. D. Observation of the Noncovalent Quaternary Associations of Proteins by ElectrosprayIonization Mass-Spectrometry. J. Am. Chem. Soc. 1994, 116, 5271-5278.

27. Lu, D.; Futterer, K.; Korolev, S.; Zheng, X.; Tan, K.; Waksman, G.; Sadler, J. E. Crystal Structure of Enteropeptidase Light Chain Complexed with an Analog of the Trypsinogen Activation Peptide. J. Mol. Biol. 1999, 292, 361-373.

28. Godavarti, R.; Sasisekharan, R. A Comparative Analysis of the Primary Sequences and Characteristics of Heparinases I, II, and III from Flavobacterium heparinum. Biochem. Biophys. Res. Commun. 1996, 229, 770-777.

29. Lohse, D. L.; Linhardt, R. J. Purification and Characterization of Heparin Lyases from Flavobacterium heparinum. J. Biol. Chem. 1992, 267, 24347-24355.

30. Sannes-Lowery, K. A.; Griffey, R. H.; Hofstadler, S. A. Measuring Dissociation Constants of RNA and Aminoglycoside Antibiotics by Electrospray Ionization Mass Spectrometry. Anal. Biochem. 2000, 280, 264-271.

31. Loo, J. A.; Hu, P. F. McConnell, P.; Mueller, W. T.; Sawyer, T. K.; Thanabal, V. A Study of Src SH2 Domain Protein-Phosphopeptide Binding Interactions by Electrospray Ionization Mass Spectrometry. J. Am. Soc. Mass Spectrom. 1997, 8, 234-243.
32. van Holde, K. E.; Johnson, W. C.; Ho, P. S. Principles of Physical Biochemistry. Prentice-Hall: Upper Saddle River, NJ, 1998; pp 599-611. 33. Carroll, K. S.; Gao, H.; Chen, H.; Stout, C. D.; Leary, J. A.; Bertozzi, C. R. A Conserved Mechanism for Sulfonucleotide Reduction. PLoS Biol. 2005, 3, e250.

34. Carroll, K. S.; Gao, H.; Chen, H.; Leary, J. A.; Bertozzi, C. R. Investigation of the Iron-Sulfur Cluster in Mycobacterium tuberculosis APS Reductase: Implications for Substrate Binding and Catalysis. Biochemistry 2005, 44, 14647-14657.

35. Vogel, G. M.; Meuleman, D. G.; Van Dinther, T. G.; Buijsman, R.; Princen, A. W.; Smit, M. J. Antithrombotic Properties of a Direct Thrombin Inhibitor with a Prolonged Half-Life and AT-Mediated Factor Xa Inhibitory Activity. J. Thromb. Haemostat. 2003, 1, 1945-1954.

36. Innis, C. A.; Hyvonen, M. Crystal Structures of the Heparan SulfateBinding Domain of Follistatin. Insights into Ligand Binding. J. Biol. Chem. 2003, 278, 39969-39977.

37. Yeh, B. K.; Eliseenkova, A. V.; Plotnikov, A. N.; Green, D.; Pinnell, J.; Polat, T.; Gritli-Linde, A.; Linhardt, R. J.; Mohammadi, M. Structural Basis for Activation of Fibroblast Growth Factor Signaling by Sucrose Octasulfate. Mol. Cell. Biol. 2002, 22, 7184-7192.

38. Zhou, H.; Casas-Finet, J. R.; Heath Coats, R.; Kaufman, J. D.; Stahl, S. J.; Wingfield, P. T.; Rubin, J. S.; Bottaro, D. P.; Byrd, R. A. Identification and Dynamics of a Heparin-Binding Site in Hepatocyte Growth Factor. Biochemistry 1999, 38, 14793-14802.

39. Middaugh, C. R.; Mach, H.; Burke, C. J.; Volkin, D. B.; Dabora, J. M.; Tsai, P. K.; Bruner, M. W.; Ryan, J. A.; Marfia, K. E. Nature of the Interaction of Growth Factors with Suramin. Biochemistry 1992, 31, 9016-9024.

40. Venkataraman, G.; Shriver, Z.; Davis, J. C.; Sasisekharan, R. Fibroblast Growth Factors 1 and 2 are Distinct in Oligomerization in the Presence of heparin-like glycosaminoglycans. Proc. Natl. Acad. Sci. U.S.A. 1999, 96, 1892-1897.

41. Alzani, R.; Cozzi, E.; Corti, A.; Temponi, M.; Trizio, D.; Gigli, M.; Rizzo, V. Mechanism of Suramin-Induced Deoligomerization of Tumor Necrosis Factor Alpha. Biochemistry 1995, 34, 6344-6350.

42. Proudfoot, A. E.; Handel, T. M.; Johnson, Z.; Lau, E. K.; Li-Wang, P.; Clark-Lewis, I.; Borlat, F.; Wells, T. N.; Kosco-Vilbois, M. H. Glycosaminoglycan Binding and Oligomerization are Essential for the in Vivo Activity of Certain Chemokines. Proc. Natl. Acad. Sci. U.S.A. 2003, 100, 1885-1890.

43. Rusnati, M.; Urbinati, C.; Caputo, A.; Possati, L.; Lortat-Jacob, H.; Giacca, M.; Ribatti, D.; Presta, M. Pentosan Polysulfate as an Inhibitor of Extracellular HIV-1 Tat. J. Biol. Chem. 2001, 276, 22420-22425.

44. Rusnati, M.; Tulipano, G.; Urbinati, C.; Tanghetti, E.; Giuliani, R.; Giacca, M.; Ciomei, M.; Corallini, A.; Presta, M. The Basic Domain in HIV-1 Tat Protein as a Target for Polysulfonated Heparin-Mimicking Extracellular Tat Antagonists. J. Biol. Chem. 1998, 273, 16027-16037.

45. Sandhoff, R.; Grieshaber, H.; Djafarzadeh, R.; Sijmonsma, T. P.; Proudfoot, A. E. I.; Handel, T. M.; Wiegandt, H.; Nelson, P. J.; Grone, H. J.Chemokines Bind to Sulfatides as Revealed by Surface Plasmon Resonance.Biochim. Biophys. Acta168752200563

46. Li, Y. T.; Hsieh, Y. L.; Henion, J. D.; Ocain, T. D.; Schiehser, G. A.; Ganem, B. Analysis of the Energetics of Gas-Phase Immunophilin Ligand Complexes by Ion-Spray Mass-Spectrometry. J. Am. Chem. Soc. 1994, 116, 7487-7493. 